PRAXIS

ecucativa

Universidad Nacional de La Pampa

Facultad de Ciencias Humanas

Instituto de Ciencias de la Educación

para la investigación interdisciplinaria

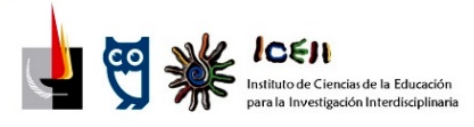

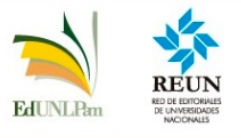

ISSN 2313-934X

SANTA ROSA, LA PAMPA, ARGENTINA

Correo electrónico: iceii@humanas.unlpam.edu.ar

Disponible en https://cerac.unlpam.edu.ar/index.php/praxis

Un trayecto de adscripción académica universitaria. Estudiantes que investigan sobre su propia formación. Articulo de Eliana Verónica Soto y Mariel Lucía Ferreira. Praxis educativa, Vol. 26, No 1 enero - abril 2022. E - ISSN 2313-934X. pp. 1-20. https://dx.doi.org/10.19137/praxiseducativa-2022-260110

Esta obra se publica bajo Licencia Creative Commons 4.0 Internacional CC BY- NC-SA Atribución, No Comercial, Compartir igual

\title{
Un trayecto de adscripción académica universitaria. Estudiantes que investigan sobre su propia formación
}

A path of university academic affiliation. Students who do research into their own training

Um caminho de ajudante acadêmico universitário: Alunos pesquisando a sua própria formação acadêmica.

\section{Eliana Verónica Soto}

Universidad Nacional de San Martín, Argentina

elianaverosoto@hotmail.com

ORCID 0000-0003-0990-4543

\section{Mariel Lucía Ferreira}

Universidad Nacional de San Martín, Argentina

mferreira@estudiantes.unsam.edu.ar

ORCID 0000-0003-1854-6856

Recibido: 2021-05-16 | Revisado: 2021-08-08 | Aceptado: 2021-09-23 


\section{Resumen}

En el presente trabajo reflexionamos sobre nuestra experiencia en co-investigación como estudiantes adscriptas de un proyecto de una Escuela de Humanidades en una universidad pública nacional del conurbano bonaerense, relatando a dos voces nuestra trayectoria en el mismo. Metodológicamente, partimos de nuestras bitácoras de trabajo, audiograbaciones y fotografías para realizar una descripción analítica de la adscripción, la cual se encuentra dividida en tres apartados: el lugar de lxs otrxs en la construcción del conocimiento, palabra en dispersión y resistencias, y espacios y cuerpos que comunican en símismos. Nuestra reflexión da cuenta de las oportunidades de aprendizaje y transformación generadas a partir de la implementación de una práctica pedagógica novedosa para nosotras. Así, observamos que se generó un espacio en vínculo con Ixs otrxs que favoreció la paridad, la comunicación en horizontalidad, y, junto a ello, la construcción colectiva de nuevos conocimientos partiendo de las epistemologías locales.

Palabras clave: aprendizaje; experiencia; investigación; democracia; adscripción.

\section{Abstract}

We present an analytical reflection on our experience as adscriptas a la investigación, a term used in Spanish to describe the role of those who volunteer as students to be in an apprenticeship relationship with experienced professors-researchers at our public university (School of Humanities) in the metropolitan area sorrounding the city of Buenos Aires. We have analyzed and written our piece in two voices, as we are both apprentices. Methodologically, we start from our work logs, audio recordings and photographs to make an analytical description of the assignment, which is divided into three sections: the place of others in the construction of knowledge, word in dispersion and resistance, and spaces and bodies that communicate in themse/ves. Our reflection accounts for the learning and transformation opportunities generated from the implementation of a new pedagogical practice for us. Thus, we observe that a space was created in connection with others that favored parity, horizontal communication, and, together with it, the collective construction of new knowledge based on local epistemologies.

Keywords: learning; experience; research; democracy; adscripción.

\section{Resumo}

No presente trabalho, refletimos sobre a nossa experiência em co-pesquisa e participação como alunos inscritos em um projeto de Escola Humanística de uma universidade pública da periferia bonaerense, contando nossa trajetória nela em duas vozes: Metodologicamente, partimos de nossos registros de trabalho, gravações de áudio e fotografias para fazer uma descrição analítica da tarefa, que se divide em três seções: o lugar do outro na construção do conhecimento, a palavra na dispersão e resistência, e os espaços e corpos que comunicar em si. Nossa reflexão dá conta das oportunidades de aprendizagem e transformação geradas a partir da implantação de uma nova prática pedagógica para nós. Assim, observamos que se criou um espaço de articulação com outros que privilegiava a paridade, a comunicação horizontal e, com ela, a construção coletiva de novos saberes a partir de epistemologias locais.

Palavras-chave: aprendizagens; experiência; pesquisa, democracia; ajudante. 


\section{Introducción}

El objetivo de este artículo es reflexionar y realizar un análisis sobre nuestra experiencia de formación en investigación como estudiantes adscriptas al proyecto de una Escuela de Humanidades en una universidad pública nacional del conurbano. Este trayecto se lleva adelante en el marco del Sistema de Adscripciones de esta, dirigido al alumnado de carreras de grado y pregrado con el objetivo de que puedan desarrollar un proceso de formación en la docencia o en la investigación, además de interiorizarse al respecto de la organización y el funcionamiento de la vida académica y que esta experiencia les permita transitar un espacio donde profundicen los estudios sobre temáticas específicas vinculadas con los temas de tesis o tesinas, proyectos de investigación, entre otros asuntos.

Si bien todos los años la Escuela de Humanidades de la universidad a la que pertenecemos lanza una convocatoria para que sus estudiantes se inscriban como adscriptos/as a una materia o a un proyecto de investigación, no todos/as suelen acercarse a esta propuesta o se animan a hacerlo. Por eso mismo, nos proponemos, a través de este artículo, promover dicha participación y lograr una motivación en el estudiantado que aún no se siente lo suficientemente fortalecido para dar ese paso.

Nos remontamos, para comenzar, a los motivos que nos movilizaron a nosotras para adscribirnos a la docencia. Primero, ambas nos sentimos convocadas por un/a otro/a que nos comentó sobre la propuesta de adscripción y por un proyecto en particular que nos interpeló. Estas dos cuestiones habilitaron un gran interés en nosotras. Ligado al interés, reconocimos una cierta incertidumbre como algo motivador: aquello desconocido, lo que primero surgió frente a ese llamado. Quienes escribimos este trabajo estamos estudiando las carreras de Educación y Comunicación, ambas alojadas en la misma Escuela de Humanidades.

Por otro lado, al integrarnos como adscriptas, queríamos poner a dialogar los saberes teóricos previos con una práctica concreta a la que se nos convocaba, no en términos de una racionalidad técnica, sino en lo que habilita una reflexión constante sobre la práctica. Buscábamos un lugar que nos permitiera construir teoría y volver a ella para buscar formas de conceptualizar la resolución de problemáticas; para construir algo nuevo, pero desde un espacio presentado como específicamente práctico. Queríamos, de esa manera, desandar el camino realizado hasta allí, exponernos a situaciones concretas que nos permitan indagar o problematicen nuestros conocimientos y nos permitan conectarnos con el campo de la educación y comunicación desde otro lugar.

El análisis que se llevará adelante aquí resulta relevante para futuros diseños pedagógicos de adscripciones en investigación. Partimos de esta consideración ya que aquella postura filosófica-política-pedagógica-didáctica' que guio la práctica de nuestras docentes coordinadoras, la cual será estudiada en el presente trabajo, habilitó aprendizajes significativos. Estos han sido el resultado de las lógicas y el modo de construir las relaciones y el vínculo con otras y otros, además de reconfigurar los distintos roles de los sujetos dentro de un equipo de trabajo. Así, se puede observar, en este tipo de prácticas, una manera de pensar los procesos de enseñanza- 
aprendizaje alternativa a aquellas que se presentan como hegemónicas. Es decir, nos encontramos aquí con una pedagogía de relaciones simétricas, en horizontalidad, que, por su mismo enfoque, está precisamente siempre en construcción continua y no es una forma dada o acabada. Este modo horizontal y simétrico de las relaciones es muy diferente al jerárquico burocrático que usualmente encontramos en las organizaciones escolares.

En sintonía con lo anteriormente señalado, a través de nuestro análisis del corpus, identificamos tres elementos clave, que organizan nuestra exposición en tres apartados: El lugar de otros y otras en la construcción del conocimiento; Palabra en dispersión y resistencias; y Espacios y cuerpos que comunican en sí mismos.

A su vez, antes del análisis, haremos explícito el marco teórico que nos permitió dar cuenta de nuestra línea de trabajo. También, mencionaremos el marco metodológico que nos permitirá recorrer los datos que se tuvieron en cuenta para encarar este trabajo, el trayecto que fuimos llevando adelante para responder a nuestro interrogante y los recortes hechos en función de los criterios establecidos para este tipo de textos y su economía, además de la perspectiva adoptada para la construcción del conocimiento y su materialización. Por último, discutiremos los resultados y estableceremos conclusiones preliminares que intentan ser una puerta para otras futuras reflexiones.

Finalmente, quisiéramos explicitar la pregunta que tomamos como punto de partida para desarrollar este trabajo y a la cual intentaremos responder: ¿qué configuración didácticaii implementaron las docentes en el marco de la adscripción en investigación que posibilitó un proceso de enseñanza-aprendizaje alternativo?

\section{Marco teórico}

En el presente artículo, partimos de definir el aprendizaje como:

- Proceso mediado, producto de la interacción con otros/as y los objetos

- Producto cultural

- Resultado de los vínculos entre pensamiento y lenguaje.

Para esto, nos basamos en los supuestos de Vigotsky $(1986,1988)$ y Bruner $(1991,1997)$ considerando, además, que el aprendizaje implica siempre un compartir y una posibilidad de encuentro. Al respecto, planteamos que los sujetos continuamente construyen significados a partir de sus encuentros con el mundo (Bruner 1991) y que esto se sitúa en contextos particulares que acompañarán en la definición de esos sentidos y el modo en cómo estos representen al mundo. Es en el vínculo con lo "otro" donde el sujeto crea y recrea el mundo que lo rodea y lo vuelve comunicable. El aprendizaje se vuelve internalización de esos significados compartidos (y también externalización).

Así, siguiendo a Bruner (1991), es nuestra participación en la cultura la que nos habilita a construir y negociar significados públicos. Sin embargo, como el mismo autor advierte, no hay una única forma de construirlos. Estos aspectos han sido demostrados por investigaciones recientes producidas desde el campo de la etnografía colaborativa y la sociolingüística combinadas, tanto 
en contextos de aprendizaje formales como no formales (Heras, 1993; Heras y Miano, 2014; Heras et al., 2017).

Por su parte, Bleger (2007) también ha realizado aportes ya clásicos que dialogan con los supuestos que presentamos y nos permite seguir ampliando dicho concepto. A diferencia del planteo tradicional, define al aprendizaje como un proceso de interacción en donde cada integrante va adquiriendo determinadas conductas o roles. Según esta perspectiva, no existe solamente una persona que enseña y otra que aprende, sino que el/la docente forma parte de este proceso que es mutuo y recíproco. Por lo tanto, el aprendizaje se co-construye junto a otros y otras e implica, asimismo, no solamente la mera transmisión de información por parte del docente, sino también que cada integrante incorpore y maneje instrumentos de problematización e indagación. Esto último, según el autor, se lograría cuando los sujetos "se hagan cargo de sus potencialidades como seres humanos" (Bleger, 2007, p. 61).

Además, y en vínculo con lo anterior, comprendemos que cada situación de encuentro se constituirá de una manera particular generando aprendizajes específicos, irrepetibles y únicos si lo pensamos en términos de huella (Aulagnier, 1993). Y es dicha situación de encuentro la que conformaría un encuadre que actuaría como sostén para la co-construcción de estos nuevos aprendizajes (Heras, 2014).

Continuando con la conceptualización realizada hasta aquí, tomar al aprendizaje como proceso de interacción implica analizar una gran variedad de elementos, ya que funciona como un complejo entramado de yuxtaposiciones, de expresiones lingüísticas y de estas en otros sistemas semióticos, tal como señalan Menti y Alam (2014): "los gestos, la dirección de la mirada, la orientación corporal, expresiones faciales, los movimientos de todo el cuerpo, la postura, la variación de la entonación y la particular estructuración del contexto de actividad" (p. 17-18). Cabe mencionar que también partimos de los aportes realizados por los autores Baylon y Mignot (1996), quienes sostienen que, en el proceso de comunicación, los espacios, objetos y disposición de las personas también influyen y comunican. En estas mismas líneas, Miano y Heras $(2015,2018)$ y Heras et al. (2021) han producido estudios que dan cuenta de aspectos similares.

A su vez, además de pensar en términos de aprendizaje, debemos detenernos a enmarcar teóricamente el modo en cómo concebimos la naturaleza de ese conocimiento que fuimos construyendo colectivamente en este trayecto de investigación en adscripción. Tomamos de Schön (1987) la idea de "practicum reflexivo". Implica un tipo de profesional que sabe manejar el arte de la reflexión en la práctica. Este, partiendo de situaciones problemáticas particulares, logra detenerse frente a eso que resulta inédito, desnaturalizar lo cotidiano y reconfigurar conocimientos antes ya concebidos para buscar soluciones apropiadas y únicas para "zonas indeterminadas" de la práctica. En ese contexto, entonces, el aprendizaje se vuelve significativo ya que se opera con una nueva forma de comprender: más reflexiva, más crítica. Pero, sobre todo, más creativa en términos de Perrenoud (2004) quien, en diálogo con Schön (1987), señala que las situaciones más complejas ameritan soluciones singulares, brindando un marco de mayor autonomía a todo profesional. Por su parte, Corneille Castoriadis ha inspirado el concepto de 
reflexión deliberada para referirse a procesos similares, un aspecto identificado y analizado por Heras (2014) para estudiar el aprendizaje producido en contextos organizacionales de grupos que se auto organizan y auto gobiernan.

\section{Metodología y análisis de datos}

Los/as adscriptos/as y las docentes fuimos participando por igual en la documentación del proceso de nuestro aprendizaje grupal a través de diversos soportes: audiograbaciones de las reuniones, bitácoras, fotografías, crónicas y audios de actividades realizadas en el campo de trabajo, resúmenes y fichas de materiales leídos, afiches y PowerPoint preparados. Esta documentación tenía dos propósitos. Por un lado, tener múltiples medios de comunicación interna de lo que íbamos realizando y aprendiendo. Por otro lado, tener un acervo documental que podría convertirse en corpus de reflexión en momentos posteriores, para cualquiera de quienes estuvimos involucrados/as. A diferencia de otras situaciones, donde se supone que son las personas que coordinan las que usarán el material para luego reflexionar y escribir sobre la experiencia, aquí, se planteó que este archivo era de propiedad colectiva y se construía cooperativamente. Las bitácoras, por ejemplo, eran narraciones escritas que cada uno/a realizaba para documentar y reflexionar sobre la experiencia. Teníamos la posibilidad de compartirlas entre los y las integrantes del equipo ya que las profesoras coordinadoras nos consultaron si queríamos construir un espacio virtual en el grupo, visible a cada participante, y estuvimos de acuerdo. Asimismo, a partir de las audiograbaciones y fotografías, pudimos registrar las reuniones e interacciones que en ellas se daban. Este material nos permitió armar un cuadro descriptivo de algunas de las reuniones, que sirve para ejemplificarlas (ver Tabla 1).

\section{Tabla 1}

Cuadro descriptivo de reuniones de junio a agosto 2019

\begin{tabular}{|l|l|l|}
\hline Fecha & Participantes & Tema/Actividades \\
\hline Junio & $\begin{array}{l}\text { Adscriptos/as, docentes y un } \\
\text { becario doctoral }\end{array}$ & $\begin{array}{l}\text { Intercambio sobre sentimientos y sensaciones individuales } \\
\text { en torno a la trayectoria en adscripción. } \\
\text { Intercambio sobre la trayectoria individual de cada } \\
\text { adscripto/a. } \\
\text { Explicitación sobre la dinámica de trabajo. } \\
\text { Presentación de conceptos centrales sobre la obra de } \\
\text { Castoriadis por parte de las docentes. } \\
\text { Propuesta de reflexionar a partir de la obra. } \\
\text { Explicación sobre técnica de transcripción (escucha y } \\
\text { lectura de un transcripto). } \\
\text { Julio }\end{array}$ \\
& $\begin{array}{l}\text { Adscriptos/as, docentes, un becarión sobre metodología de categorización. } \\
\text { doctoral y un invitado: David Burin }\end{array}$ & $\begin{array}{l}\text { Presentación del invitado. } \\
\text { Explicitación sobre la dinámica de trabajo. }\end{array}$ \\
\hline
\end{tabular}




\begin{tabular}{|c|c|c|}
\hline & & $\begin{array}{l}\text { Planteo de dudas administrativas. } \\
\text { Intercambio desencadenado a partir de comentarios de } \\
\text { adscriptos/as sobre sus desempeños en la adscripción. } \\
\text { Reflexión sobre la apropiación que hicimos de la oficina en } \\
\text { la universidad. } \\
\text { Revisión sobre los proyectos. } \\
\text { Conexión entre adscripción, proyectos y teoría en materias } \\
\text { vistas en la universidad (escrito de conceptos y autores } \\
\text { mencionados en un afiche). } \\
\text { Propuesta de armado colectivo de fichas de resúmenes o } \\
\text { afiches. } \\
\text { Discusión en torno a la experiencia de adscripción en } \\
\text { relación con la universidad. } \\
\text { Explicación del género proyecto de investigación. } \\
\text { Presentación de una experiencia a cargo del invitado y } \\
\text { miembro de esta. } \\
\text { Intercambio y análisis a partir de la presentación. } \\
\text { Discusión en torno a un software de almacenamiento y } \\
\text { base de datos de un proyecto. } \\
\text { Explicación sobre libro co-gestionado producto de la } \\
\text { experiencia que nos relató el invitado. } \\
\text { Invitación a propuesta de encuentro. } \\
\text { Se comparten las tareas asumidas. } \\
\text { Explicación e intercambio sobre técnicas de desgrabación y } \\
\text { trabajo de campo (entrevistas). } \\
\text { Discusión sobre la posibilidad de retomar con la apertura } \\
\text { con juegos. } \\
\text { Dinámica de cierre con palabras claves. }\end{array}$ \\
\hline Agosto & $\begin{array}{l}\text { Adscriptos/as, docentes y un } \\
\text { becario doctoral }\end{array}$ & $\begin{array}{l}\text { Apertura con juego. } \\
\text { Revisión de tareas propuestas. } \\
\text { Intercambio sobre distintos métodos de desgrabación y } \\
\text { programas utilizados. } \\
\text { Presentación y lectura de un texto. } \\
\text { Proyección y escucha de una desgrabación. } \\
\text { Planteo de dudas sobre la técnica de transcripción. } \\
\text { Conexión entre la adscripción y saberes traídos de materias } \\
\text { cursadas en la universidad (escrito de conceptos y autores } \\
\text { mencionados en un afiche). } \\
\text { Explicación sobre las entrevistas como género discursivo: } \\
\text { qué variantes hay y por qué se producen, cómo se generan } \\
\text { las interacciones en las conversaciones y las entrevistas } \\
\text { (proyección de diapositivas). } \\
\text { Planteo de dudas sobre las entrevistas. }\end{array}$ \\
\hline
\end{tabular}


A los fines de este artículo, partimos de reunir y organizar el material que produjimos durante la adscripción, tal como se ve en la Tabla 2. Luego, a partir de nuestra interrogante, tomamos la decisión metodológica de utilizar únicamente nuestras bitácoras, las fotografías y las audiograbaciones de las reuniones. En función de este recorte, pudimos generar un corpus que nos ha permitido responder a nuestro interrogante sobre cuál fue la configuración didáctica que implementaron las docentes en el marco de la adscripción que posibilitaron un proceso de enseñanza-aprendizaje alternativo.

\section{Tabla 2}

Archivo, procedimiento, selección y racionalidad

\begin{tabular}{|c|c|c|c|}
\hline ARCHIVO & $\begin{array}{l}\text { PROCEDIMIENTO } \\
\text { ANALÍTICO/DECISIONES }\end{array}$ & $\begin{array}{l}\text { SELECCIONADO PARA } \\
\text { CORPUS }\end{array}$ & RAZÓN DE LA SELECCIÓN \\
\hline $\begin{array}{l}\text { Bitácoras de todos/as, } \\
\text { incluidas las bitácoras } \\
\text { docentes }\end{array}$ & $\begin{array}{l}\text { Relectura de las } \\
\text { bitácoras }\end{array}$ & $\begin{array}{l}\text { Selección de las } \\
\text { nuestras. }\end{array}$ & $\begin{array}{l}\text { Partimos de nuestra reflexión sobre la } \\
\text { adscripción. Consideramos que esta es } \\
\text { algo que se fue construyendo y } \\
\text { complejizando, necesitábamos volver } \\
\text { a las primeras reflexiones. }\end{array}$ \\
\hline Audiograbaciones & $\begin{array}{l}\text { Escucha y tabulación de } \\
\text { la información. Posterior } \\
\text { análisis. }\end{array}$ & sí & $\begin{array}{l}\text { Para analizar los intercambios, el } \\
\text { modo en cómo se organizaban los } \\
\text { encuentros, de qué manera circulaba } \\
\text { la palabra, la multiplicidad de tareas } \\
\text { propuestas. }\end{array}$ \\
\hline Fotografías & $\begin{array}{l}\text { Visualización de } 15 \\
\text { fotografías }\end{array}$ & sí, tres & $\begin{array}{l}\text { Seleccionamos las fotografías que } \\
\text { consideramos que representan las } \\
\text { diversas instancias de intercambio } \\
\text { generadas durante las reuniones. }\end{array}$ \\
\hline $\begin{array}{l}\text { Textos leídos (artículos } \\
\text { publicados de diferentes } \\
\text { autores/as) }\end{array}$ & $\begin{array}{l}\text { Relectura de los trabajos } \\
\text { compartidos }\end{array}$ & sí & $\begin{array}{l}\text { Elegimos algunos de los autores que } \\
\text { nos inspiraron ya que guiaron } \\
\text { nuestros enfoques en cuanto a la } \\
\text { investigación y los conceptos } \\
\text { desarrollados, pero hay otros que no } \\
\text { han sido incluidos en el artículo } \\
\text { debido a que profundizaban y } \\
\text { complejizaban ciertas miradas que, por } \\
\text { una cuestión de economía, no } \\
\text { podíamos realizar. }\end{array}$ \\
\hline $\begin{array}{l}\text { PowerPoint, carteles } \\
\text { afiche, otros elementos } \\
\text { generados para } \\
\text { explicaciones }\end{array}$ & Visualización y relectura & no & $\begin{array}{l}\text { Decidimos utilizar estos materiales } \\
\text { para incorporar en futuras reflexiones } \\
\text { a realizar. }\end{array}$ \\
\hline
\end{tabular}


Antes de continuar avanzando, nos gustaría dejar explícito el modo en cómo fuimos ordenando la narración que dio lugar a este trabajo. Comenzamos preguntándonos sobre el sistema de adscripciones en particular, dialogando entre nosotras sobre nuestros propios caminos hasta llegar a la adscripción, caminos que fueron, en ambos casos, consecuencia de la presencia de un/a otro/a que posibilitó que fuera posible. Aquí, construimos una de las categorías que nos permitió objetivar varios de los aspectos que fuimos identificando en nuestras bitácoras, a saber: Trayectorias de vida que dialogan.

Asimismo, al momento de revisar el corpus (audiograbaciones, fotografías y nuestras bitácoras), identificamos el rol de la escritura durante la adscripción, y lo describimos de acuerdo con las funciones que podíamos identificar que cumplía la escritura según el material del corpus. Así, vimos que la escritura cumplía todas estas funciones: escritura para pensar; escritura para objetivar nuestro conocimiento; escritura para comunicarnos entre los miembros del grupo; escritura para comenzar a desarrollar procedimientos analíticos. Esto desencadenó que iniciemos un primer proceso de categorización en donde "bitácora como registro" era una categoría. En función de esto, pudimos generar subcategorías como "propiedad colectiva" y "construcción de conocimiento", las cuales refieren a la construcción de saberes a partir de la colaboración con otros/as y de la autoreflexión. Sin embargo, decidimos iniciar un segundo proceso de categorización ya que el existente no nos permitía indagar en otros aspectos del diseño pedagógico implementado. No obstante, al continuar con la revisión del corpus, fuimos visibilizando otras interrogantes que aluden a la didáctica, a la paridad, a la democratización de la palabra, a la incomodidad hacia la propiedad colectiva y a la cuestión de las diferentes trayectorias e historias de vida de los/as adscriptos/as. Interrogantes que fuimos transformando en categorías analíticas.

En consecuencia, decidimos realizar una tercera categorización en donde unificamos o excluimos las distintas categorías creadas en el primer y segundo proceso de categorización, a la vez que agregamos otras que consideramos relevantes para el análisis. Creamos así, finalmente, las siguientes categorías analíticas a usar en este artículo:

- Paridad y democratización de la palabra: refieren a la participación de adscriptas/os y docentes de manera horizontal.

- Incomodidad. es cuando se visibiliza una cierta incomodidad frente la práctica pedagógica implementada.

- Trayectorias de vida que dialogan. aluden a la construcción de conocimiento partiendo de las epistemologías locales.

- Construcción de conocimiento: es cuando se hace referencia a la construcción de saberes a partir de la autoreflexión y de la interacción con otras/os.

- Distancia-cercanía: refieren a los vínculos entre espacio y cuerpo generados durante la interacción.

- Confianza-vínculos con los/as otros/as. cómo interfieren en los procesos de aprendizaje. La presencia de otros/as como mediadores de la construcción del conocimiento, como 
facilitadores de espacios para la construcción y reflexión. Aquí, aparece, también, la cuestión del trabajo colaborativo.

\section{Presentación del análisis}

En el apartado anterior, dimos cuenta de cómo fuimos construyendo las categorías a las cuales apelaremos a la hora de realizar nuestro análisis: paridad y democratización de la palabra, incomodidad, trayectorias de vida que dialogan, construcción de conocimiento, distancia-cercanía y confianza-vínculos con los/as otros/as.

La identificación de estas en los distintos registros que tenemos dio como resultado una combinación constante y en diálogo entre estas, lo cual no nos ha permitido construirlas como objetos a analizar de forma singular. Se retroalimentan, se sostienen y funcionan en esa interacción. Esto se liga a la idea de que esta propuesta didáctica y su efectuación no se piensa como la suma de elementos aislados, sino en el diálogo constante y en la hibridación de variables que se retroalimentan de manera que no se las pueda separar. En función de este planteamiento, procederemos a analizarlas a través de tres apartados distintos en donde las categorías que se ven afectadas pueden repetirse e ir fluctuando entre un apartado y otro:

- El lugar de otros y otras en la construcción del conocimiento: refiere a la colaboración en la construcción de saberes considerando al equipo de trabajo como un colectivo donde cada cual aporta desde su trayectoria y recorrido. Se pondrán en juego las categorías: trayectorias de vida que dialogan, construcción de conocimiento, confianza-vínculo con los/as otros/as.

- Palabra en dispersión y resistencias. relacionado a la participación entre adscriptas/os y docentes de manera horizontal, esta ha impactado en las distintas subjetividades generando, en algunos casos, resistencias y malestares. Se incluyen las categorías: incomodidad, paridad y democratización de la palabra.

- Espacios y cuerpos que comunican en sí mismos. se pone el foco en el modo en cómo los cuerpos y espacios entran en juego en la construcción del conocimiento con otros y otras. Categorías implicadas: distancia y cercanías, construcción del conocimiento y democratización de la palabra.

\section{El lugar de otros y otras en la construcción del conocimiento}

A comienzos de marzo de 2019, se inició formalmente, dentro del sistema de adscripciones, nuestra experiencia formativa en investigación. Más adelante, destacaremos algunas nociones con respecto a las experiencias formativas en investigación previas de las cuales nosotras mismas no éramos conscientes hasta encontrarnos con el equipo de esta experiencia.

El equipo estaba conformado por María Amalia Miano y Ana Inés Heras, las docentes, y por adscriptos/as de distintas carreras de grado de la universidad (Educación, Estudios de la Comunicación y Psicopedagogía). Asimismo, durante los encuentros mensuales, solían participar, por un lado, invitadas/os de distintas experiencias que dialogaban con los proyectos involucrados 
en esta investigación y, por el otro, un becario doctoral de intercambio que nos brindaba asesoramiento en herramientas digitales para facilitar nuestras tareas. Cabe mencionar que este equipo estaba conformado por adscriptos/as de otro proyecto de investigación dirigido por Heras, con quienes trabajábamos en mutualidad y paridad en la colaboración de las distintas tareas ya que dichos proyectos dialogaban y los aportes de uno retroalimentaban el trabajo en el otro.

En efecto, nuestra formación en investigación humanística comenzó con la interacción con los y las integrantes del equipo. Partiendo de la idea de que el aprendizaje se construye en interacción con otros/as (Heras, 1993, 1995), es fundamental destacar el vínculo generado entre las personas participantes, ya que fue un factor determinante para la gestión de conocimiento y resignificación de nuestras prácticas como estudiantes, un hecho que fuimos percibiendo a lo largo de la adscripción:

En ese "ser parte de" las relaciones interpersonales juegan un rol muy importante: hay una imperiosa necesidad de construir una mirada introspectiva para, en mi reconocimiento como individuo con específicas competencias y/o habilidades, enriquecerme con la presencia de otro. (Bitácora de Soto, 2019)

Partiendo de esta premisa, podemos reflexionar sobre cómo, en este proceso, los/as otros/as se configuraron también como fuente de indagación y saber. Cuando pensamos en esto, se nos viene a la mente la figura de "hombre-libro" que Bradbury (1953) creó en su novela Fahrenheit 451. Frente a un mundo distópico donde los libros eran quemados, los hombres-libro tenían la tarea de leer y guardar en su memoria esas narraciones de los libros que se quemarían. Cada uno de esos sujetos guardaba en sí una narración que tendría que atesorar para, en un futuro, compartir con los demás. En analogía, los/as compañeros/as de la adscripción se construyeron como piezas valiosas en un proceso donde cada cual aportaba una manera de hacer y narrar distinta en función de sus trayectorias de vida y saberes previos. Por ejemplo, durante la adscripción:

Cada integrante se comprometió a realizar diversas tareas, algunas individuales y otras grupales, que fueron asignadas por Heras y Miano, pero fueron distribuidas en función de lo que cada uno/a de nosotros/as expresó tener interés en realizar. Por ejemplo, yo manifesté que deseaba participar en jornadas de trabajo de campo, realización de transcripciones y tareas de análisis. (Bitácora de Ferreira, 2019)

Asimismo, se puede seguir ejemplificando con los abordajes teóricos y metodológicos durante las reuniones mensuales del equipo, en donde, a la hora de emprender el análisis de algún artículo, las miradas se multiplicaban, lo que puede observarse en las dinámicas señaladas en la Tabla 1: de esta forma, el acercamiento al objeto de estudio se enriquecía. Se puede mencionar, por ejemplo, el comentario de un adscripto: "Yo estoy haciendo un programa de radio ahora y tiene bastante que ver con esto de las entrevistas" registrado de una las reuniones (agosto, 2019), en donde él trae un ejemplo de sus vivencias para reflexionar en torno al tema que estábamos abordando en ese momento: qué son las entrevistas como género discursivo, qué 
variantes hay y por qué se producen, cómo se generan las interacciones en las conversaciones y las entrevistas.

Por otro lado, es pertinente mencionar los momentos de diálogo, debate e, inclusive, expresión de diferencias (teóricas, personales, existenciales) durante las reuniones, que servían como espacios de reflexión sobre las tareas que cada uno estaba realizando. En el cuadro descriptivo (ver apartado Metodología, Tabla 1) hemos buscado describir y objetivar qué tipo de actividades llevábamos a cabo en cada encuentro y, mientras que escuchábamos las audiograbaciones, fuimos percibiendo que durante las presentaciones de las tareas realizadas cada uno/a iba expresando cómo se sentía respecto a ellas como, por ejemplo, observamos en el mes de junio. Asimismo, cabe mencionar que, en estas interacciones, comenzamos a visualizar la cooperación existente en nuestro equipo, conocer nuestras capacidades y limitaciones, y valorar las capacidades de todos y todas, ya que cada aporte que un integrante del equipo realizaba se complementaba con los aportes del resto del equipo.

Además, si bien cada encuentro estaba previamente planificado y se explicitaba el orden del día al comenzar, gran parte de las dinámicas que se generaban durante las reuniones estaban atravesadas por inquietudes espontáneas e interrogantes que iban surgiendo al interior del propio encuentro. Un solo elemento puesto a rodar en la mesa desencadenaba otros procesos de conexión y triangulación que alentaban la construcción de una nueva dirección en las tareas y reconfiguraban las maneras de comprender al objeto en sí, mediado por los aportes que cada cual brindaba. A continuación, presentamos un fragmento del audio de una de las reuniones en donde observamos la situación que se genera a partir del intercambio reflexivo sobre la escucha de una entrevista:

Eliana dice que desgrabar a Amalia es tremendo por la cantidad de intervenciones con muletillas que utiliza. A partir de este comentario, empiezan a reflexionar sobre las entrevistas y desgrabaciones. Amalia comparte sus primeras experiencias entrevistando y desgrabando. Ana dice que todas esas cuestiones que fueron comentando las podrían ver en una próxima reunión escuchando algunas grabaciones. Ana comenta sus interpretaciones luego de escuchar sus propias entrevistas. Mariel comenta que la toma de palabra constante puede tener relación con la toma de poder. Ana reflexiona sobre la intervención de Mariel preguntándole por qué cree que le respondió "obvio" que puede hablar. Mariel responde: "Porque querés que participemos más nosotros". Se genera una reflexión sobre la toma de palabra. (Reunión de adscriptos/as, julio, 2019)

En la secuencia que presentamos anteriormente, que corresponde a nuestra reunión mensual de julio, observamos cómo, a partir del comentario de Eliana, se produce una reflexión grupal en torno a las entrevistas y desgrabaciones, que culmina con Ana sugiriendo una nueva actividad para la próxima reunión. Asimismo, este fragmento nos permite seguir visibilizando las situaciones de intercambio reflexivo generadas entre nosotros/as, lo cual habilita las categorías trabajadas por Schön (1987) en tanto cada encuentro de adscripción nos permitía reflexionar eny sobre la práctica ya que, por un lado, traíamos las dificultades y problemas que se nos habían 
planteado a la hora de llevar adelante las actividades y tareas propias del campo, pero, por otro lado, había que dar respuestas a las mismas en dichos encuentros y, entonces, conjuntamente, se improvisaban de modo reflexivo soluciones a dichas problemáticas. Esto se fue volviendo parte de cada reunión: ingresaba un elemento problemático, se brindaban posibles situaciones y esas propias experiencias de reflexión nos invitaban a ir comprendiendo de modos distintos, construyendo categorías diferentes que se adaptaran a cada situación particular. Nos acercábamos así al practicum reflexivo (Schön, 1987).

\section{Palabra en dispersión y resistencias}

El trayecto de adscripción no solo nos abrió paso al mundo de la investigación, sino que también funcionó como puerta para pensar al conocimiento como construcción colectiva. Fuimos así entendiendo que uno de los enfoques que estábamos estudiando (Castoriadis, 1994) permitía -al mismo tiempo que ser estudiado en sus nociones teóricas - fundamentar la práctica de trabajo conjunto y también guiarnos para comprender lo que estábamos haciendo allí. Por ejemplo, un hecho que se encuentra fuertemente entrelazado a la idea de democratización de la palabra es la forma concreta que tienen las interacciones (aspecto que comenzamos a estudiar desde la perspectiva de la sociolingüística interaccional) y también las orientaciones (significaciones imaginarias sociales, según Castoriadis, concepto que también comenzamos a estudiar) que sostienen el marco conceptual para ese ejercicio.

A través de lo que fuimos mencionando con anterioridad, fuimos visibilizando la existencia de un espacio que fomenta nuestra participación, nuestra toma de palabra y, a través de ello, nuestro aprendizaje. De hecho, a partir de la primera reunión del equipo, comprendimos "que ese espacio sería distinto a lo que en el imaginario social se construye como el estereotipo de la clase universitaria":

Llegamos al lugar pautado y ahí estábamos todxs los adscriptxs entre los nervios y la ansiedad. Ana y Amalia llegaron y nos tendieron un abrazo a cada unx. Nos sentamos alrededor de una mesa sin saber dónde ubicarnos en un principio, ellas nos señalaron que lo hagamos donde estemos más cómodxs. Nos preguntaron si tomábamos mate y si alguien quería aprovechar para ir al bar, también hubo algún que otro chiste. Inmediatamente, para iniciar el encuentro, Ana nos propuso un juego para presentarnos y nos pidió permiso para grabar. Cada participante fue contando cómo llegó ahí y también surgieron intervenciones ligadas a lo que cada cual podía aportar u hacer. Supimos ese mismo día que una de nuestras coordinadoras sabía hablar al revés. Otro dato, no menor, es que en ese encuentro nos llevamos como tarea el completar una tabla donde indicaríamos cada cual qué actividad estaba dispuestx a realizar y cuál no, además de considerar qué habilidad teníamos o conocimientos con los cuales pudiésemos aportar. (Soto, comunicación personal, febrero, 2021)

Claramente, esta dinámica no se construyó como habíamos previsto de acuerdo con nuestras expectativas de lo que era un espacio formal de adscripción. En este sentido, esta 
situación generó un quiebre y, a su vez, esto habilitó a configurarnos de un modo distinto: ocupando un rol activo, apropiándonos de un modo diferente del espacio y en una relación diferente con las docentes y pares. Así, lo que se puso en juego y materializó fue una dinámica de grupo que, como se ha mencionado con anterioridad, giraba en torno a cómo cada integrante aportaba un recurso o habilidad para abordar el trabajo de acuerdo con su experiencia y trayectoria y, a partir de ahí, generaba nuevos conocimientos en esa interacción y retroalimentación.

Sin embargo, la democratización de la palabra generó algunas resistencias, ansiedades e incertidumbres. En una reflexión posterior, pudimos ubicar que estas ansiedades tenían origen en al menos tres cuestiones: 1) por no comprender la totalidad en la que nos enmarcábamos; 2) por creer que lo que hacíamos no sumaba (nos autoevaluábamos sin tener noción de qué era "la suma" que supuestamente esperábamos) y 3) no estábamos acostumbradas a una lógica que se va construyendo al hacer y para la que no hay una agenda total determinada, ni roles fijos (sino que pueden rotar y modificarse), ni una temporalidad igual para todos/as (de hecho, cada adscripto/a tuvo su propio pulso y el ritmo se construyó con pulsos muy variados, sonoridades distintas y variantes de muchos tipos). Estábamos entrando en una lógica que no conocíamos y generaba muchas preguntas. Al respecto, en varias reuniones del equipo, surgieron reflexiones y preguntas sobre la adscripción que dieron lugar a otros interrogantes (ver cuadro en apartado Metodología).

Escolarizados/as durante toda la vida, y manejando de manera automática cierta lógica individualista y de construcción del saber para una acreditación, el espacio de adscripción y el modo para aprender a hacer investigación se nos presentaba como algo distinto. Caminábamos en búsqueda de algo sin saber del todo qué sería al final ( $y$, en todo caso, eso era lo esperado) y, además, junto a otros/as en una gran diversidad de tareas: transcripciones, entrevistas, análisis de fuentes teóricas, armado de fichas, invitaciones a participar de diversos encuentros. Un camino diferente al transitado en la carrera se nos abría paralelamente.

Recapitulando, lo innovador de nuestra experiencia de adscripción, en particular, tiene que ver con esta didáctica cogestionada por las directoras a partir de la cual los vínculos de poder se cuestionaban y eso repercutía en el modo en cómo los saberes marginales, ahora pensados en términos de epistemologías locales, encontraban terreno y se resignificaban en una nueva experiencia formativa. Si pensáramos el aprendizaje en la adscripción a partir de la tradicional tríada saber-alumno/a-docente, varios elementos que aquí intentamos esbozar quedarían por fuera y nos sería casi imposible determinar el modo en cómo logramos generar aprendizaje significativo. Claramente, una mirada superadora implica pensar que, a la hora de analizar estas situaciones de formación, es necesario tener en cuenta varios elementos que, al ser modificados o movidos, repercuten en las demás piezas. Un aspecto que es crucial y está por fuera de la tríada es el grupo/lo colectivo. Para pensar en este objeto de análisis, primero podríamos detenernos en la idea de interacción, eje que desarrollaremos en el siguiente apartado. 


\section{Espacios y cuerpos que comunican en sí mismos}

Como veníamos observando, nuestra formación en investigación se construyó en interacción con otras/os. Sin embargo, como explicitamos en el marco teórico, consideramos que las interacciones se completan con la yuxtaposición de las expresiones lingüísticas junto a otros sistemas semióticos. Debido a ello, también tomamos como objeto de análisis las fotografías que documentan el espacio físico en donde se llevaron a cabo nuestras reuniones, junto a los objetos presentes en este y a nuestra comunicación no verbal (posturas, gestos y distancias proxémicas). Hemos seleccionado tres fotografías para mostrar algunas de las instancias de intercambio generadas durante las reuniones:

\section{Figura 1}

Reunión de adscriptos/as 2019. Coordinadora exponiendo

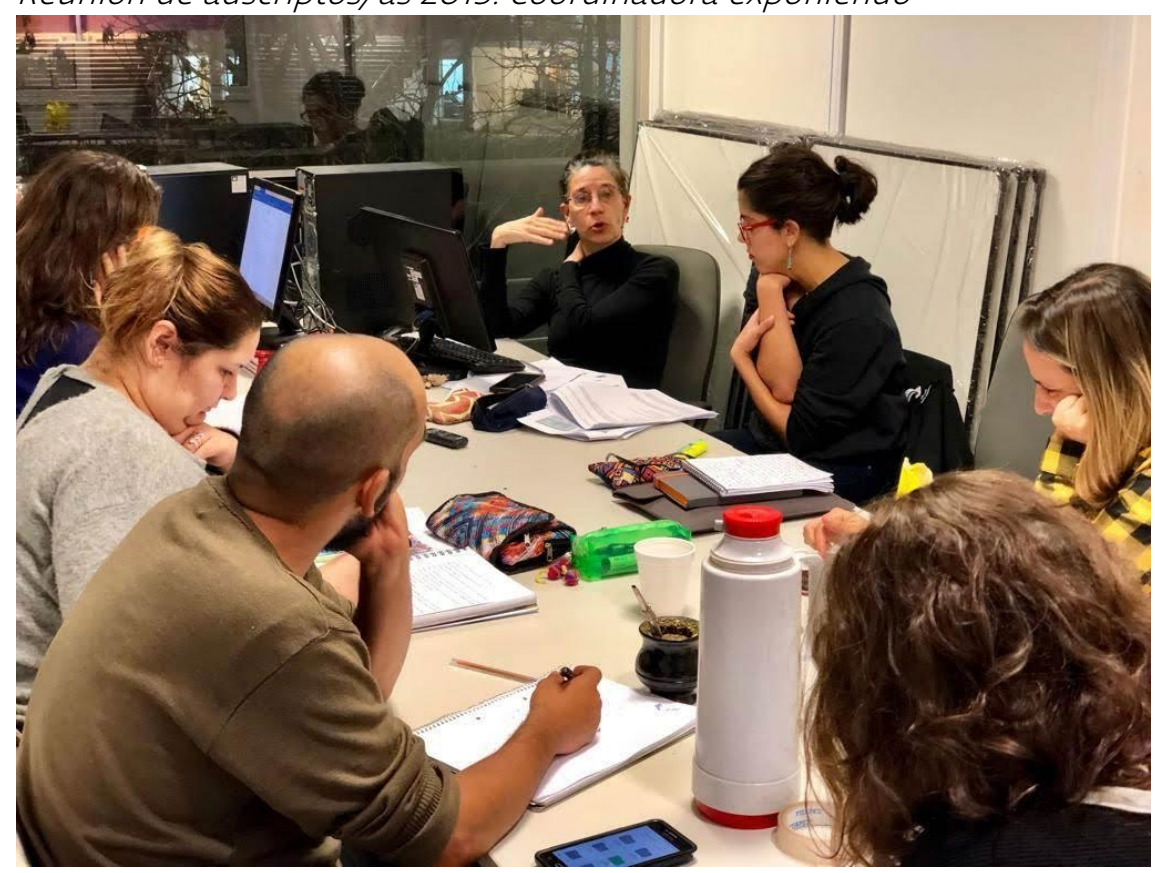




\section{Figura 2}

Reunión de adscriptos/as, 2019. Participantes dialogando

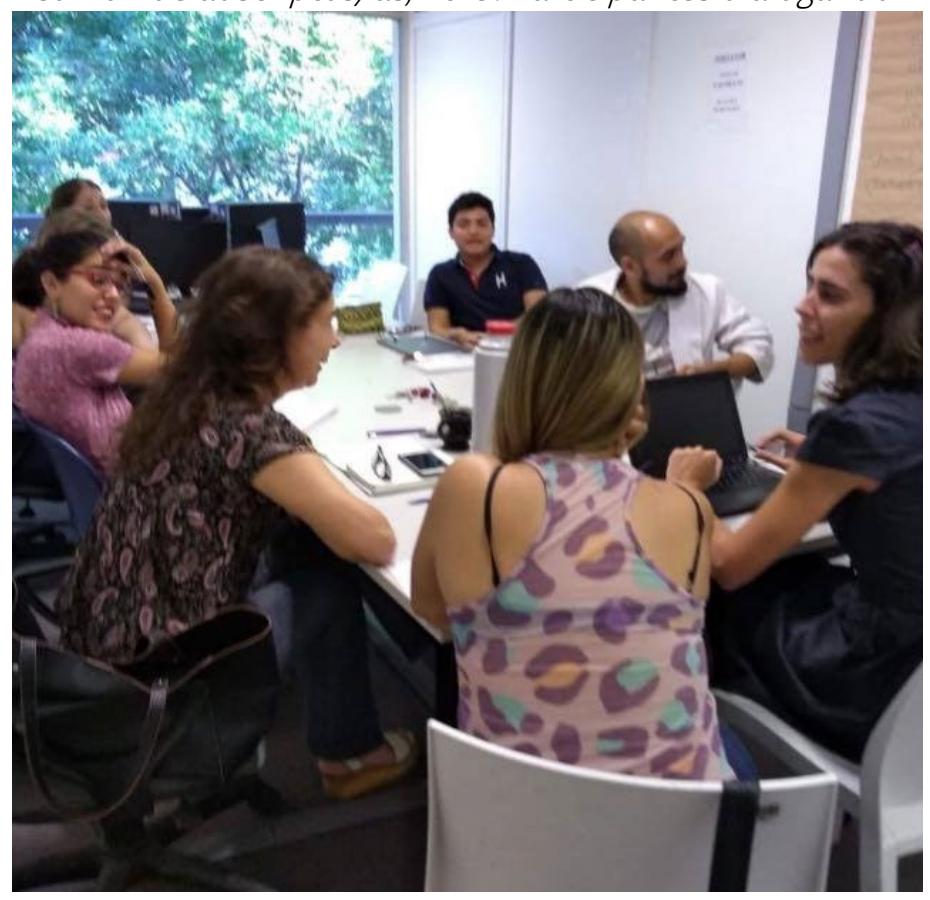

\section{Figura 3}

Coordinadoras en propuesta lúdica

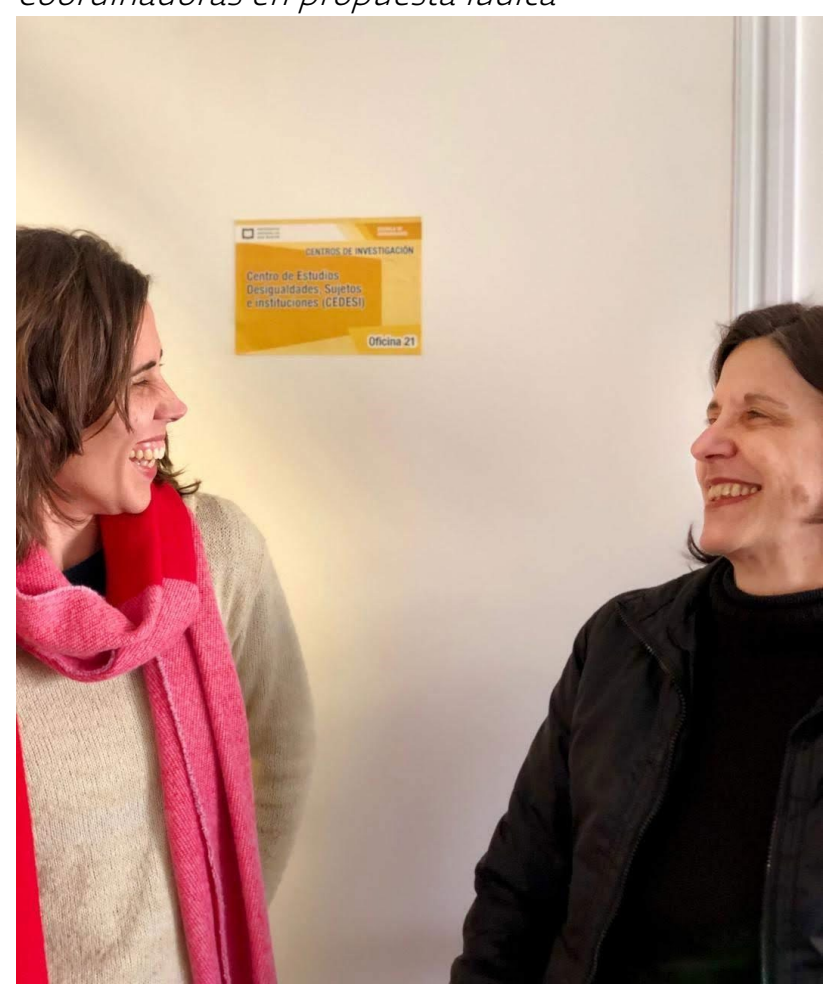


Luego de observar las dos primeras fotografías, analizamos que existe una distribución espacial que difiere de la frecuente en aulas universitarias (pupitres colocados en filas). En la oficina, hay una única mesa rectangular que, además de tener encima materiales de trabajo (computadoras, libros, fotocopias, cuadernos, etc.), posee una bebida: el mate. En relación con las distancias proxémicas, percibimos que cada uno/a de nosotros/as establece una cercanía mayor o menor con su compañero/a, pero que, en todos los casos, la distancia suele oscilar entre íntima y personal (Hall, 1966).

En la primera fotografía, visualizamos a una de las docentes hablando y al resto de nosotros/as concentrados/as mientras escuchamos o tomamos notas en cuadernos. La concentración, además de percibirla en la toma de notas, la observamos porque nuestras posturas parecen indicar que estamos evaluando el mensaje emitido y, simultáneamente, extrayendo conclusiones de este. Aunque también analizamos que la postura de una de las adscriptas parece indicar una cierta incomodidad, ya que mientras se encuentra escuchando y mirando a la docente mantiene una postura ligeramente encorvada de su espalda y cruza los brazos. Como resultado de haber participado de las reuniones, comprendemos que la incomodidad reflejada en su postura puede ser producto de la incomprensión, ya que la cámara captura el momento en donde la docente explica una pregunta que fue planteada por esa misma adscripta.

En la segunda fotografía, observamos que la cabecera de la mesa es ocupada por una de las docentes y por una de nosotras. Asimismo, a diferencia de la primera fotografía, por un lado, aquí no se encuentra una docente hablando y al resto tomando notas, sino que existe una dispersión de la palabra. Por otro lado, analizamos que las computadoras de escritorio son utilizadas por todos/as, ya que, en las dos primeras fotografías, observamos a distintas personas usándolas. Esto último es consecuencia de que las docentes nos explicitaron que las computadoras podían ser usadas por todos/as. De hecho, a partir de esa explicitación, una de nosotras dos comenzó a utilizarlas en cada reunión mensual.

En la última fotografía, observamos a nuestras dos docentes estableciendo una distancia cercana mientras se ríen y miran entre ellas. Cabe mencionar que esta situación fue producto de un juego llevado a cabo al inicio de la reunión, el cual generó bastantes sonrisas y risas entre nosotros/as.

A partir de las interpretaciones de las imágenes anteriores, en función de una clave de lectura que es consecuencia de haber participado de las reuniones, analizamos que el espacio, nuestro lenguaje corporal y la presencia de determinados objetos efectivamente influyen y comunican sentidos. Por ejemplo, estudiamos la cabecera de la mesa, ya que suele ser una ubicación preestablecida en donde quien tiene más poder la ocupa. Sin embargo, aquí, observamos que no hay ubicaciones preestablecidas en las reuniones, ya que tanto las directoras como nosotros/as estamos sentados/as en diferentes lugares en ambas fotografías. Esto último puede ser un indicativo del establecimiento, por un lado, de relaciones en horizontalidad y, por otro lado, de la puesta en funcionamiento de un recurso pedagógico para lograr esa horizontalidad. Asimismo, también podemos analizar los objetos, nuestros gestos y posturas 
porque pueden significar la generación de situaciones de encuentro amistosos para la mayoría de nosotros/as, los cuales parecen favorecer el intercambio y las relaciones en paridad: el mate, el cual forma parte de la cultura popular argentina, rompe con la formalidad de las reuniones de trabajo; la mesa rectangular y las ubicaciones que no están preestablecidas parecen promover el diálogo en vez de obturar la comunicación; y los gestos y posturas de concentración, pero también las sonrisas y las distancias cercanas entre cada una/o de nosotras/os, hablan de un vínculo afectivo entre nosotras/os que parece propiciar la co-construcción de nuevos aprendizajes.

\section{Conclusiones}

A lo largo de este trabajo, hemos intentado realizar una descripción analítica de nuestro paso por la adscripción. Por un lado, esto nos permitió reflexionar sobre los aprendizajes construidos en términos de vínculos no solo con distintos objetos de estudio, sino en paridad con otros/as. Aprender, en este sentido, implica una experiencia de mediación con el mundo y, por ende, en esta, nos vinculamos no solamente con las cosas, sino con las personas. Y es en ese tipo de diálogos donde se da lugar a la transformación: performativa y subjetiva. La experiencia atravesada permitió que esto se dé en términos de relaciones de poder horizontales y democratizadoras de ese espacio y en el acceso al conocimiento.

A su vez, nos propusimos pensar en una práctica formativa distinta que se nos presentó como innovadora frente a lo que ya conocíamos: esta abrió paso a múltiples preguntas, así como a situaciones de incomodidad y resistencia. Prueba de esto, como ya se ha señalado, han sido las bajas de algunos/as de los/as participantes en la adscripción. Partiendo de la idea de que cada espacio y hasta cada currículum implica una lucha constante entre los elementos y sujetos que lo constituyen, podemos considerar que toda práctica pedagógica es dinámica y su impacto sobre los sujetos depende del grado de aceptación y permeabilidad de quienes son atravesados/as por la misma.

Asimismo, consideramos que este tipo de prácticas demuestra el poder de los procesos continuos de subjetivación positiva que tienen sobre los participantes, generando espacios de aprendizajes significativos, por lo que pueden ser pensadas como propuestas para otros espacios de trabajo ya sea académicos o en otros contextos, alineadas a actividades de cogestión y autonomía, cuestión que quedará por fuera de esta presentación para futuros análisis y escrituras. Consideramos, además, que esto pudo darse así porque el vínculo entre teoría y práctica se reconfiguró de un modo permanente en este espacio, lo que nos permitió significarlo de modo diferente. Comprender que estas implican conocimientos de naturalezas distintas, pero que pueden entrar en diálogo de forma reflexiva, sin interponer una sobre otra, es clave para revisar la forma en cómo se pueden trabajar en espacios curriculares que se suelen pensar de manera aislada a las "prácticas" o suelen desplazarla de sus programas.

Para finalizar, podemos decir que hemos respondido provisoriamente al interrogante propuesto: cuando nos preguntamos por la configuración didáctica puesta en juego en este tipo de práctica educativa-formativa, debemos pensar en un elemento plural y colectivo, dinámico e 
híbrido. La construcción de aprendizaje significativo se ha generado considerando las epistemologías locales, democratizando la palabra, habilitando tareas múltiples y construyendo propiedad colectiva. Los vínculos atravesados por la confianza en el otro también han sido claves, pero eso es algo que quedará por fuera de este análisis, al igual que la pregunta sobre los motivos que empujan u obstaculizan al alumnado a inscribirse y formar parte de este tipo de experiencias formativas. Esto último surge como un elemento emergente de la observación realizada en nuestra experiencia: no todos/as suelen acercarse a este tipo de propuestas o se animan a hacerlo.

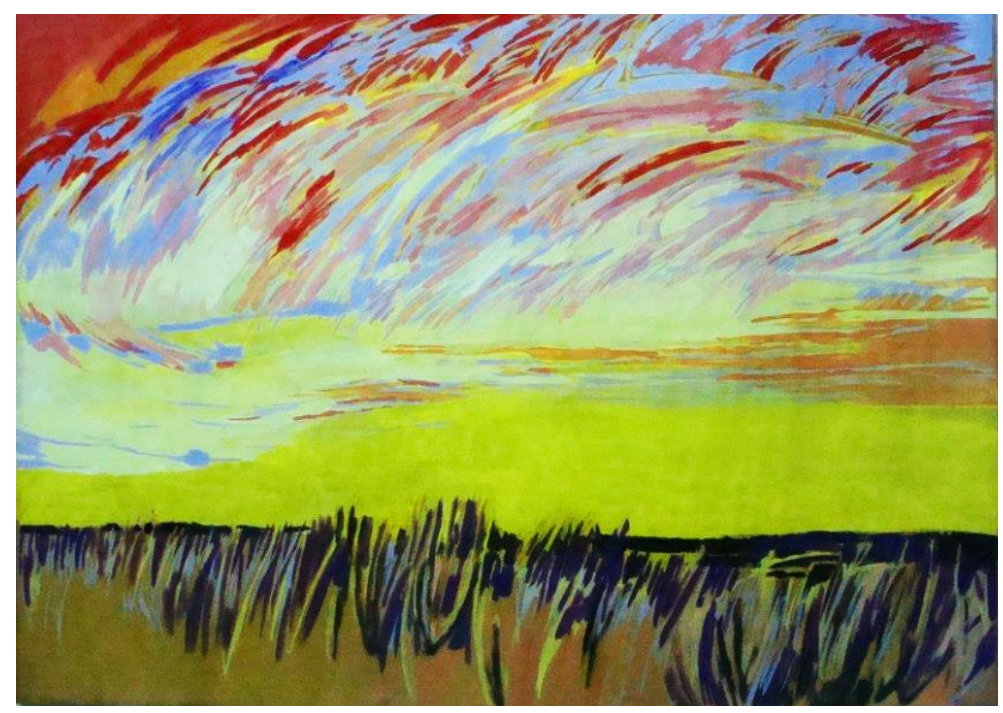

Llano, acrílico sobre papel. Paula Boh

\section{Bibliografía}

Aulagnier, P. (1993). La violencia de la interpretación. Amorrortu.

Baylon, C. y Mignot, X. (1996). La comunicación. Cátedra.

Bleger, J. (2007). Temas de psicología. Entrevista y grupos de aprendizaje. Nueva Visión.

Bradbury, R. (1996) [1953]. Fahrenheit 451. Minotauro

Bruner, J. (1991). Actos de Significado. Alianza Editorial.

Bruner, J. (1997). La educación, puerta de la cultura. Aprendizaje Visor.

Castoriadis, C. (1994). "La democracia como procedimiento y como régimen". Intervención en el encuentro realizado en Roma por el Centro Internacional por la Reforma del Estado, febrero 1994.

Freire, P. (1985) [1970]. Pedagogía del Oprimido. Siglo XXI.

Hall, E. T. (1966). The hidden dimension. Doubleday.

Heras, A. I. (1993). The construction of understanding in a sixth grade bilingual classroom. Linguistics and Education, 5(3-4), 275-279.

Heras, A. I. (1995). Living Bilingual, Interacting in Two Languages: An Ethnographic and Sociolinguistic Study of a Fourth Grade Bilingual Classroom (Tesis doctoral). Santa Barbara, Universidad de California. 
Heras Monner Sans, A. I. (Coord.). (2014). Autores nucleados en la Mesa Colectiva de Trabajo. La autonomía como proyecto. Procesos de reflexión deliberada en experiencias de auto-gestión. De Pueblos y Fronteras, 8 , 56-91.

Heras Monner Sans, A. (2014). Lógica colaborativa y generación de conocimiento colectivo: alcances y tensiones en las relaciones investigación-sociedad. Población \& Sociedad, 27(2), 137-150.

Heras, A. I. y Miano, A. (2014). Sociolingüística y etnografía. Análisis de interacciones en la Mesa de grupos auto-gestionados. La Trama de la Comunicación, 18, 251-271.

Heras, A. I., Miano, A. y Pagotto, M. A. (2017). Una apuesta por la vida: ética y estética en formas colectivo solidarias. Revista Nómadas, 46, 129-149.

Litwin, E. (1997). Las configuraciones didácticas. Una nueva agenda para la enseñanza superior. Paidós.

Menti, A. B. y Alam, F. (2014). Los gestos y la enseñanza de palabras poco familiares: ¿cuándo emplean las maestras información gestual? Bellaterra Journal of Teaching and Learning Language \& Literature, 7(1), 17-32. Miano, M. y Heras, A. I. (2015). Imágenes y narración: análisis de un espacio pedagógico con niñas y niños en situación de calle. Ciencia, Docencia y Tecnología, 26(50), 161-187.

Miano, M. y A. I. Heras (2018). Niñas y niños toman la palabra: el potencial formativo de la narración. RLCSN, 16(2), 979-994.

Schön, D. (1987). La formación de profesionales reflexivos. Hacia un nuevo diseño de la enseñanza y el aprendizaje en las profesiones. Paidós.

Vygotsky, L. (1986). Pensamiento y Lenguaje. La Pléyade.

Vygotsky, L. (1988). El desarrollo de los procesos psicológicos superiores. Grijalbo.

\footnotetext{
' Hacemos uso de esta concepción ya que, durante los encuentros de adscriptos/as, las docentes coordinadoras explicitaban continuamente que se basaban en la pedagogía libertaria propuesta por Paulo Freire (1970), entre otros/as autores/as, y también los preceptos filosóficos y educativos de Luis Iglesias, las hermanas Cossettini y los especialistas del campo de la autogestión pedagógica francesa. Estas propuestas conciben a la educación de forma diferente a las relaciones educador/a-educados/as dominantes en los centros educativos. Aquí, no se entiende a la enseñanza como el mero acto de transmitir conocimientos a estudiantes, sino que se posiciona a estos/as últimos/as en condiciones de poder comprender y criticar el mundo mediante una reflexión y acción que se realiza dialógicamente. Es decir, los roles del educador y educado se desdibujan para dar lugar a un proceso formativo en donde ambos/as aprenden y enseñan juntos/as. De tal manera, los y las estudiantes se van posicionando como críticos de la realidad que, en sus relaciones con esta, se les presenta como posible a modificar, como una realidad que no es estática, sino que puede transformarse a través la intervención.

ii Tomamos la conceptualización de Litwin (1997) sobre configuración didáctica como "manera particular que despliega el docente para favorecer los procesos de construcción del conocimiento" (p. 97).

iii Cabe aclarar que el becario participaba también para aprender a coordinar grupos universitarios.
} 